SAGE Joven es un grupo formado por gastroenterólogos jóvenes con ganas de generar actividades, estrechar lazos y escuchar propuestas.

Conocenos más en: www.sage.org.ar/sagejoven

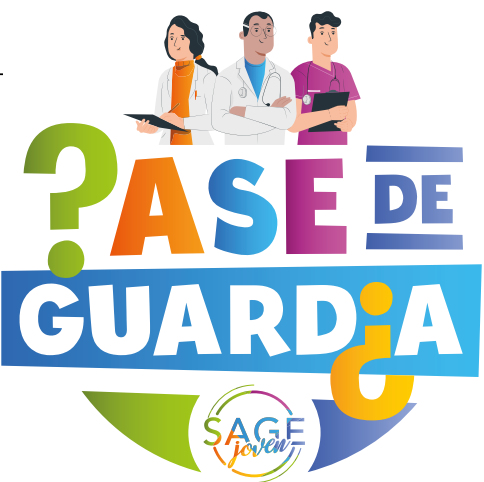

\title{
Solución del caso. Disfagia esofágica y múltiples impactaciones alimentarias
}

\section{Viene de la página 415}

\section{Solución del caso}

Se recibió el informe de la biopsia. Se realizó la coloración con la técnica hematoxilina-eosina. Se observó el epitelio esofágico parcialmente erosionado con presencia de exudado fibrinoleucocitario. Otros fragmentos mostraban al epitelio pavimentoso con hiperqueratosis, presencia de capa granular, acantosis leve, vacuolización de la capa

Figura 4.

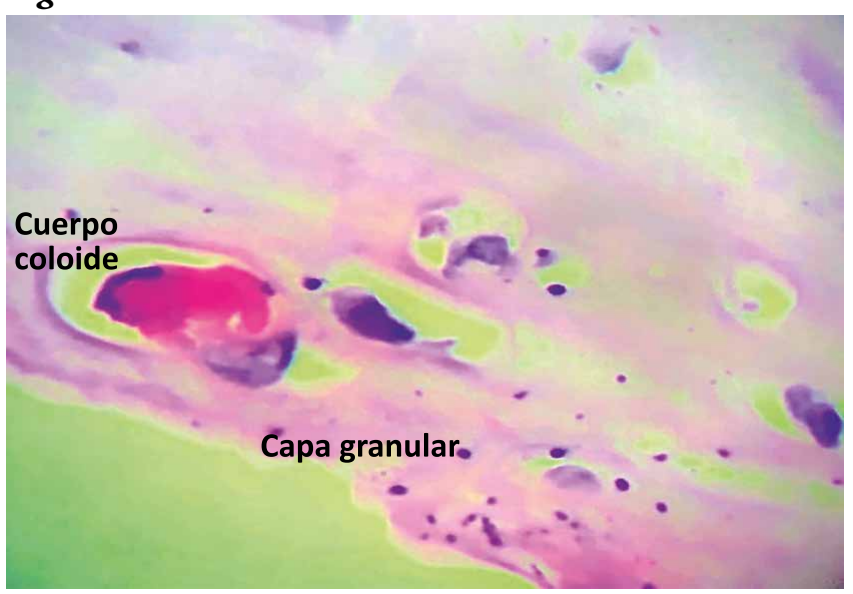

Se evalúo en conjunto con el servicio de Dermatología. Se decidió el inicio del tratamiento con Deltisona $10 \mathrm{mg} /$ día; con mejoría significativa del cuadro clínico.

El liquen plano es una enfermedad cutáneo-mucosa basal con algunos linfocitos intraepiteliales y la presencia de abundantes cuerpos coloides. Coexistían algunos linfocitos intraepiteliales, unos eósinofilos y unos polimorfonucleares neutrófilos.

Diagnóstico: esofagitis erosiva; probablemente relacionada con la patología de base: liquen plano, forma ulcerativa o erosiva (Figura 4 y 5 ).

\section{Figura 5.}

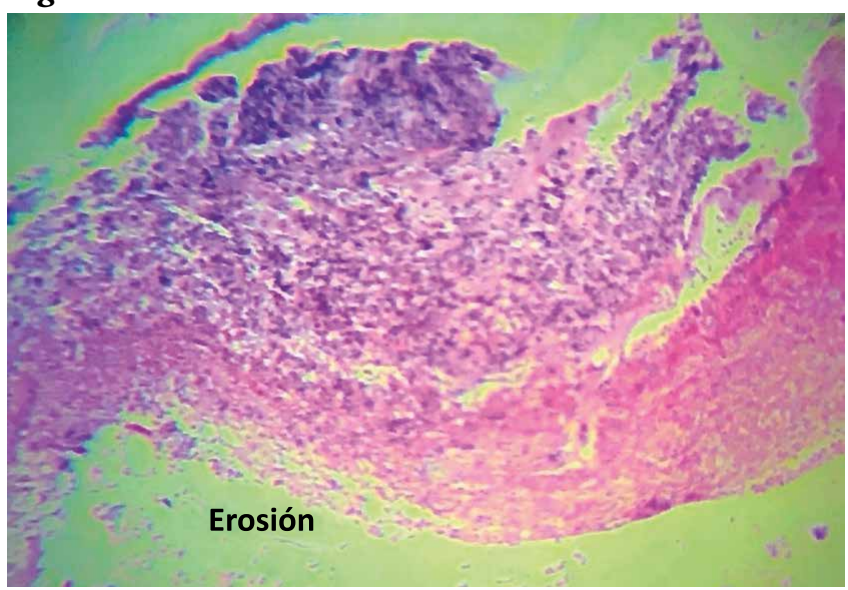

relativamente común, aunque la afectación esofágica sintomática es excepcional. Sin embargo, es probable que la prevalencia de las lesiones esofágicas se haya infraestimado: es así que cuando se realizó una endoscopia digestiva alta 
a los pacientes con liquen plano cutáneo, se encontró una afectación esofágica en un $26 \%$ de los casos. ${ }^{1}$

La afectación mucosa y, especialmente, la del esófago es mucho más frecuente en el sexo femenino. ${ }^{2}$ La etiología es desconocida, pero se han descrito asociaciones con otras entidades como la diabetes mellitus, la hipertensión arterial y ciertas hepatopatías. Puede ser el debut de una hepatopatía crónica por el VHC. ${ }^{2,3}$

La mayor parte de los pacientes se encuentran asintomáticos, pero pueden referir un dolor retroesternal, disfagia y odinofagia.

Habitualmente, las lesiones se localizan en el tercio superior del esófago, pero pueden afectar toda su longitud o únicamente el tercio inferior.

En la exploración endoscópica, la mucosa esofágica presenta un aspecto friable, con áreas erosionadas que sangran con facilidad y que, en ocasiones, se encuentran cubiertas por unas membranas que se desprenden fácilmente al roce con el endoscopio. ${ }^{4}$ No es infrecuente la aparición de estenosis de diferente cuantía. ${ }^{5}$
El diagnóstico se establece mediante una VEDA y un estudio anatomopatológico de las lesiones. Los hallazgos histológicos son característicos y consisten en un infiltrado inflamatorio en banda constituido fundamentalmente por las células $\mathrm{T}$ maduras de localización subepitelial y una degeneración de los queratinocitos de la capa basal del epitelio (cuerpos de Civatte). ${ }^{6}$

\section{Referencias}

1. Dickens CM, Heseltine D, Walton S, Bennet JR. The oesophagus in lichen planus: an endoscopic study. BMJ 1990; 300: 84.

2. Bobadilla J, van der Hulst RW, ten Kate FJ, Tytgat GN. Esophageal lichen planus. Gastrointest Endosc 1999; 50 (2): 268-271.

3. Daoud MS, Gibson LE, Daoud S, el-Azhary RA. Chronic hepatitis C and skin diseases: a review. Mayo Clin Proc 1995; 70 (6): 559-564.

4. Ukleja A, DeVault KR, Stark ME, Achem SR. Lichen planus involving the esophagus. Dig Dis Sci 2001; 46 (10): 2292-2297.

5. Lefer LG. Lichen planus of the esophagus. Am J Dermatopathol 1982; 4 (3): 267-269.

6. Abraham SC, Ravich WJ, Anhalt GJ, Yardley JH, Wu TT. Esophageal lichen planus: case report and review of the literature. Am J Surg Pathol 2000; 24 (12): 1678-1682. 